Society for the Anthropology of Work • Essential Labor

\title{
Essential or Expendable? \\ The Construction Trades \\ on the Frontlines of Late \\ Capitalism
}

Julie Shepherd-Powell

Published on: Jul 09, 2020

DOI: $10.21428 / 1 \mathrm{~d} 6 \mathrm{be} 30 \mathrm{e} . e e 5 f c a b 2$

License: Creative Commons Attribution 4.0 International License (CC-BY 4.0). 
On an unusually sunny and warm afternoon in late March, amid the "new normal" of teleworking, I was drinking a cold beer on my back deck in the Blue Ridge Mountains when news flashed across the tiny screen of my iPhone. North Carolina Governor Roy Cooper, like many governors in other states, was issuing a stay-at-home order, with only essential employees to report to work. I looked up at my husband, who had just joined me after getting off his shift at a local electrical company. "Fuck," I said. "How are we going to make ends meet?" Yet the impending financial stress of this situation was muted by another feeling-relief. I had been teaching two undergraduate courses and one graduate course online, plus attending numerous Zoom meetings for faculty committees and other administrative duties, but I had also been acting as homeschool mom, lunch lady, house cleaner, fitness coach, chef, and grocery shopper for our family of four, which includes a second- and a fifth-grader. Finally, I was going to have some help at home. I didn't have to be the mom with all the jobs.

But this is not what ended up happening. It was only a few hours later, after a few exchanges of text messages with coworkers and a closer read of the North Carolina executive order, that we figured out that my husband, an electrician, was classified as an essential worker. His duties for the past few months had been overseeing the electrical installation at a new mixed-use, high-end apartment building (read: luxury student housing and retail space) near the campus of Appalachian State University, where I work. 


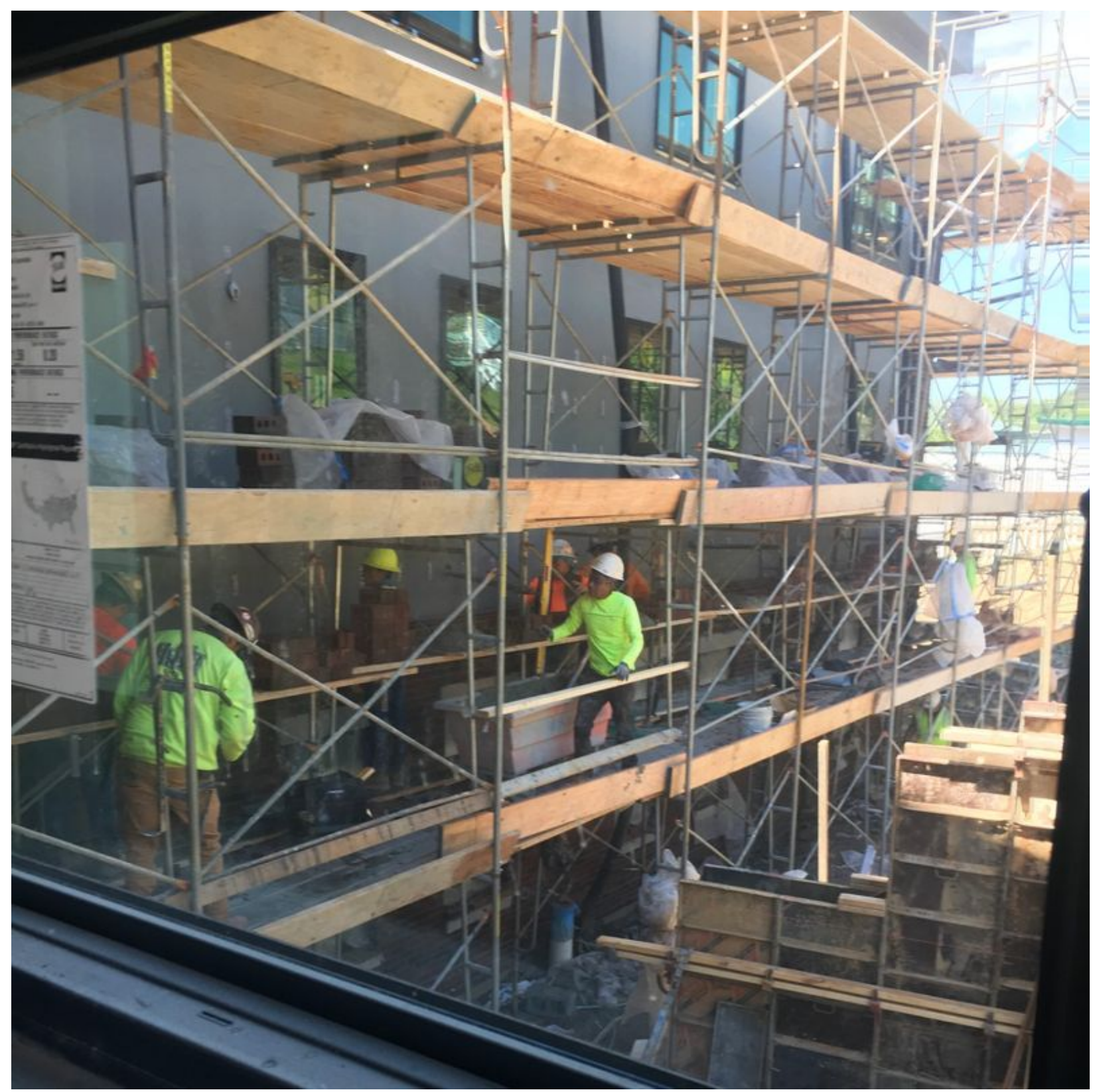

Brick masons work without masks or social distancing, May 2020. Photo courtesy of Adrian Shepherd-Powell.

Despite the fact that universities had suspended all face-to-face classes (including my own), that students were being asked to leave their residence halls for the rest of the academic year, and that the biggest sporting events (like March Madness) were being canceled, leaving fans devastated, my husband's work continued as usual. Forty tradespeople, from electricians to plumbers, drywallers to brick masons, HVAC technicians to general contractors, are on the job site every day. At the beginning of March, there were only two porta-johns in service for all forty workers. A couple of weeks after the executive order, two more arrived, but they were only cleaned once a 
week and poorly at that. Finally, two hand-washing sinks arrived, and bosses started encouraging workers to wear masks. 


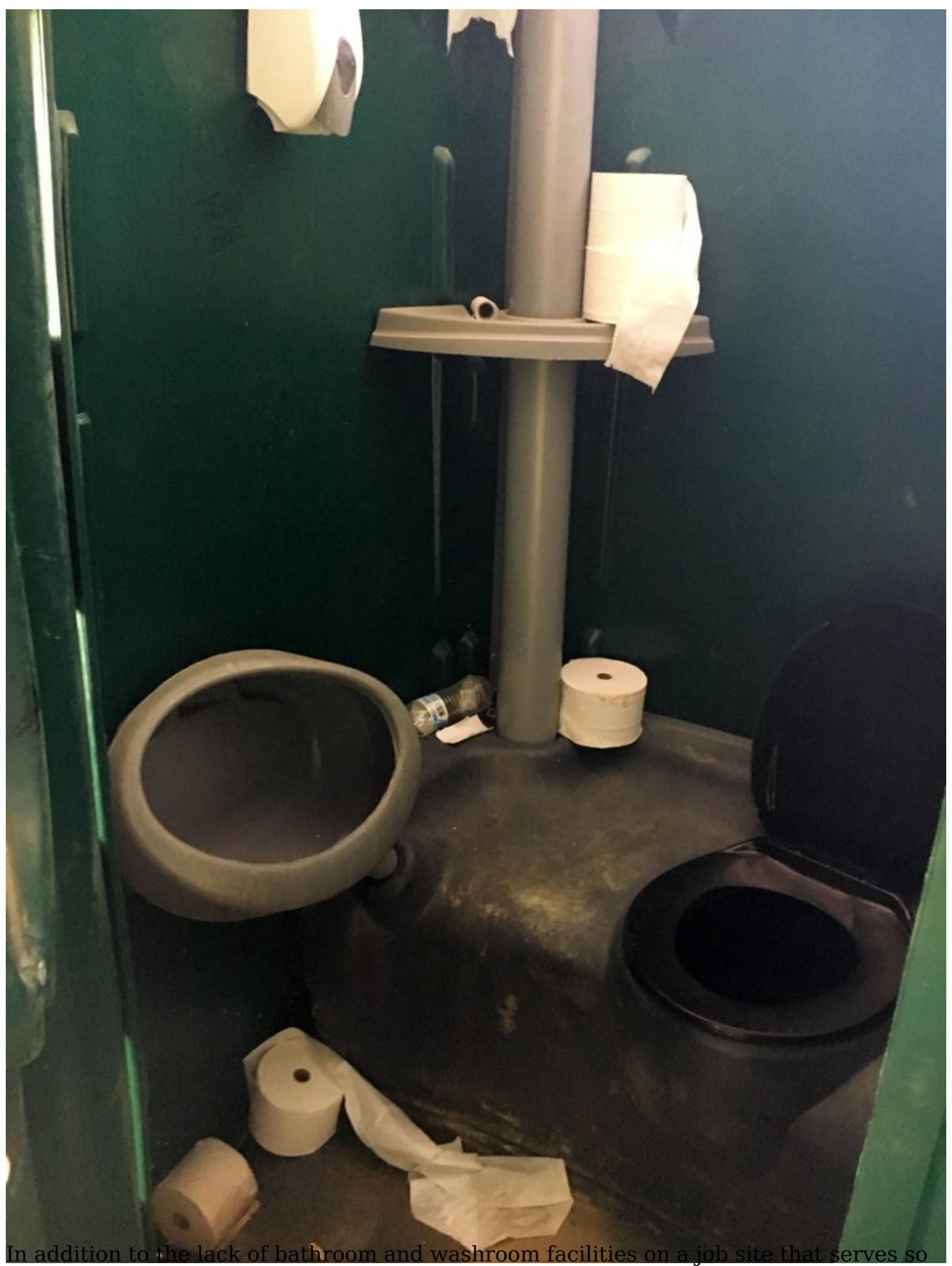

many workers, no extra cleaning is done. There has been no wiping down of railings in 
the stairwell (the only way to move through the building), no sanitizing of window and door handles that are touched on a daily basis. Furthermore, workers at the site are not just coming from our small community, which has had only twelve COVID-19 cases to date and no known community spread. The drywall contractors drive to the job from Winston-Salem, a small city less than two hours away, in an area with almost 900 cases. Other tradespeople drive over the border from neighboring Tennessee, where the restrictions on mask wearing, social distancing, and businesses have been much more lax, resulting in many more cases of COVID-19 per capita. In other words, despite not having many cases in our small community, workers arrive every day from elsewhere, meaning that job sites like this are creating a potentially volatile situation. A recent announcement from the local health department revealed that sixteen subcontractors on another campus construction site had tested positive for coronavirus, but all were residents of other communities. Sites like the one where my husband works seem to be waiting for a similar flare-up before shutting down.

It's also worth noting that certain trades are made up of almost entirely Latino/a workers, many of whom are not able to speak English, making communication difficult for the mostly monolingual site leads. It's uncertain as to whether any of these workers are undocumented, but if so, it means that they are at even greater risk given their constrained access to health care and other services, and of course, no government stimulus checks to help tide them over.

I asked my husband what it was like to work on a job site with forty people during the early stages of the pandemic, and he explained that for a while, the trades tried to practice social distancing - with the drywallers on one side of the building and the electricians on the other. But a tight schedule to finish the project before August, when students are supposed to arrive back to our small college town, as well as pressure from the general contractor and owner of the building, have meant that social distancing has given way to the fast pace of "get it done as quickly as possible, no matter the costs." This has meant that my husband, who had been working forty hours a week Monday through Friday, is now working fifty to sixty hours six days a week, increasing his potential exposure time. On any given day, my husband reports that just a few people on the site are wearing masks. Coupled with the lack of social distancing and the extended working hours, this adds up to a big risk to all of the workers' health and safety for the sake of making a capitalist all the richer.

While my university pushes to reach its arbitrary goal of "20,000 (students) by 2020" and the developer pushes for overtime to finish construction before a reopening that 
may or may not be possible, we are left wondering: is my husband's job as an electrician essential or is it rather that he, as a working-class tradesperson, is expendable?

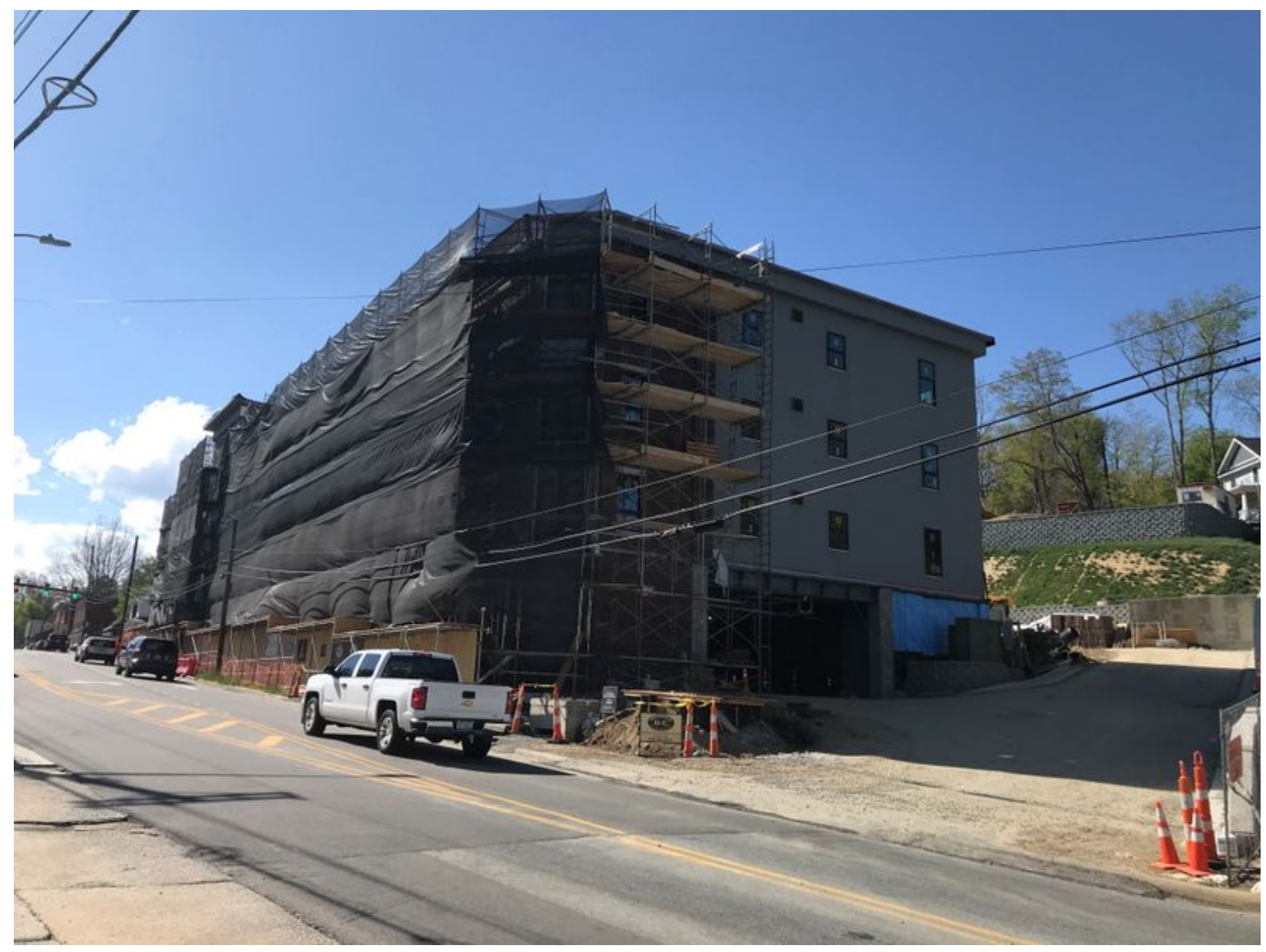

Roadside view of the student apartment complex. Photo by Julie Shepherd-Powell.

This planned increase in student enrollment has provided an unparalleled opportunity for local real-estate developers to make money, especially on new apartment complexes close to campus. These units are by no means affordable for western North Carolina (\$1200-1600 per month for single-occupancy units), but students whose parents have the means will pay for the convenience and location-just steps away from campus and close to the restaurants and bars downtown. And the complex that my husband is working on is certainly not the only site that continues with lax health and safety measures amid the pandemic. Many faculty members and students at Appalachian State have criticized the increase in enrollment, citing the lack of resources-from classroom space and housing to instructors and mental health counselors-available to serve these additional students. The continued 
neoliberalization of education is not lost on the majority of people who make up our university. Yet despite these criticisms of unfettered growth, it should be stressed that the security of academic jobs at our institution, including my own as an assistant professor, are dependent on the labor of the tradespeople who keep our campuses running. We faculty are also implicated in this system.

In a recent article, the geographer David Harvey bemoaned that the working class is bearing the brunt of the pandemic, either by working jobs considered essential (like grocery store workers and nurses) or by being laid off from jobs and left with almost no resources. In addition to the societal divide of those who can work at home (CEOs and college professors) and those who cannot (health-care workers and meatpackers), Harvey argues that a second divide separates those workers who do and do not have the ability to stay at home and isolate or quarantine (whether with or without pay). The class divide in this country, often ramified along racial, ethnic, and gender lines, proves to be even more exposed during the pandemic.

Perhaps even more telling than this critique of neoliberalism is the concept that Harvey develops elsewhere of accumulation by dispossession. This process, in Harvey's argument, ramps up during times of overaccumulation-that is, high unemployment and a "glut of commodities on the market that cannot be disposed of without a loss." With a soaring unemployment rate at $14.7 \%$ in the United States and oil prices plummeting to an all-time low of negative $\$ 40$ a barrel in late April, it's no doubt that we are in such a time. And the use of "essential" workers to make money for capitalists at the risk of their health, safety, and lives demonstrates a new kind of accumulation by dispossession. Harvey shows that this process has gone well beyond the taking of land or resources to include things like patents on genetic materials, the commodification of cultural forms, and intellectual property rights. What is new during COVID-19 is that that dispossession also takes hold of workers' health and life. We have long known that workers in environmentally hazardous jobs, such as those working in chemical plants in Cancer Alley along the Mississippi River, have experienced a devaluing of health and safety, but the response to the COVID-19 pandemic expands this dispossession further. It's not just the workers doing jobs widely known to be hazardous that are paying the price with their bodies; now, it's workers everywhere, from checkout clerks to tradespeople working on luxury apartments.

Workers like my husband are producing surplus value despite the risk to their health, and yet there is no surplus compensation for the extra risk they are shouldering. As my 
husband pointed out to me, there's no extra hazard pay to help if someone becomes hospitalized, no funeral pay if someone dies, and for some, not even the baseline of health insurance. While historically some workers have received hazard pay for risky work (such as during natural disaster cleanups), there's no such thing for essential workers in the current moment. Even the most recent push for the HEROES Act, which does provide hazard pay for workers on the frontlines, fails to include workers such as tradespeople who are putting their lives at risk. They often take this risk because they have no other options. They cannot afford to lose the insurance their job provides, they may not be eligible for unemployment if they are not technically "laid off," and meanwhile bills continue to pile up.

A few weeks ago, I asked my husband what he thought of being labeled an essential worker, thrown into a category that includes health care providers and emergency personnel. He responded: "I think the essential worker label is bullshit for those outside of the medical fields and at lower income levels. There's no other outlet to get paid, so we go to work. The other option is to not work and not get money." My husband is grateful to have the work and I am grateful to have the income it provides us, but ultimately the question should not be whether we are grateful for his job but why we must continue to choose between making a living and his health and safety. If the government can bail out corporations during the pandemic, why can't it pay a living wage to workers whose only essentiality is to make more money for capitalists? Workers deserve better.

It is not that the devaluing of the labor force is new, or that capitalists have not been profiteering off disaster well before this pandemic. But what is different is the scale of recklessness and the greater willingness to risk human lives. The COVID-19 pandemic has shed light on the darkest corners of our economic system, showing that the essential in "essential worker" sometimes really means essential for making money for someone else.

\section{Author Bio}

Julie Shepherd-Powell is Assistant Professor and Graduate Program Director at the Center for Appalachian Studies at Appalachian State University. Her current research focuses on local environmental movements against natural resource extraction and energy regimes in southern and central Appalachia.

\section{Preview Image}

Courtesy of Gilbert Mercier. 
